\title{
Electrochemical and Corrosion Behavior of Nanocrystalline TiNi-Based Alloys and Composite
}

\author{
M. BALCERZAK*AND M. JURCZYK \\ Institute of Materials Science and Engineering, Poznań University of Technology, \\ pl. M. Skłodowskiej-Curie 5, 60-965 Poznań, Poland
}

\begin{abstract}
In this work TiNi-based nanocrystalline alloys and composite were produced by mechanical alloying process with subsequent annealing at $750{ }^{\circ} \mathrm{C}$ for $0.5 \mathrm{~h}$. Mechanical alloying was performed in a SPEX 8000 Mixer Mill. TiNi alloy was chemically modified by $\mathrm{Ag}$ elemental powder. Silver content equaled $5 \mathrm{wt} \%$. X-ray diffraction analyses revealed formation of $\mathrm{TiNi}$ main phase after annealing. Additionally, two minor phases $\mathrm{Ti}_{2} \mathrm{Ni}$ and $\mathrm{TiNi}_{3}$ were detected for unmodified alloy. Crystallites of obtained powders were nanosized. Corrosion and electrochemical measurements were performed in $6 \mathrm{M} \mathrm{KOH}$ solution. All synthesized materials were used as negative electrode for $\mathrm{Ni}-\mathrm{MH}_{x}$ batteries. Ag addition positively affects on stability of discharge capacity of TiNi alloy during of charge/discharge tests.
\end{abstract}

DOI: 10.12693 /APhysPolA.126.888

PACS: 82.47.Cb, 88.30.rd

\section{Introduction}

Titanium-based hydrogen storage alloys have been considered as candidates for hydrogen storage and for negative electrodes in $\mathrm{Ni}-\mathrm{MH}_{x}$ batteries. TiNi alloy absorb and desorb hydrogen at room temperature. This alloy revealed a discharge capacity equaled $150 \mathrm{mAh} / \mathrm{g}$ at a discharge current of $30 \mathrm{mAh} / \mathrm{g}$. Application of microcrystalline TiNi material in metal-hydrogen systems is limited due to poor absorption/desorption kinetics and complicated activation procedure [1-3].

Chemical composition, microstructure of material and size of alloy crystals are one of the most important factors in metal-hydrogen systems. Ti-Ni type alloys can be produced by mechanical alloying (MA). This process which consist of repeated fracturing, mixing and cold welding provides formation of new nanostructured, nonequilibrium alloys [4]. Nanocrystalline TiNi alloy obtained by MA was studied by us in the past. Electrochemical discharge capacity was higher than for microcrystalline alloy and amounted $171 \mathrm{mAh} / \mathrm{g}$. Improvement of mentioned properties is caused by reduction of powder size and creation of new clean surfaces [5].

Electrochemical properties of alloys for $\mathrm{Ni}-\mathrm{MH}_{x}$ batteries can be also improved by chemical modification. Replacement of Ni element by transition metals may improve activation properties of TiNi alloy [1, 2, 4]. Addition of $\mathrm{Pd}$ and multiwalled carbon nanotubes positively influences electrochemical properties and improves cycle stability of electrode [6].

Silver can be also used to ameliorate discharge capacity of $\mathrm{Ni}-\mathrm{MH}_{x}$ electrode. Shin et al. sintered $\mathrm{ZrMn}_{0.6} \mathrm{~V}_{0.2} \mathrm{Co}_{0.1} \mathrm{Ni}_{1.2}$ with Ag to form pellet. Discharge capacity was also related to content of $\mathrm{Ag}$ in studied

* corresponding author; e-mail: mateusz.balcerzak@put .poznan.pl material [7]. Positive effect of silver addition was also observed in La-rich $\mathrm{AB}_{5}$-type alloy. Ag affected on electrochemical reduction reaction rate of oxygen and cycle life of hydrogen storage [8].

In this work structure, agglomerate size and morphology, corrosion and electrochemical properties in $6 \mathrm{M}$ $\mathrm{KOH}$ were measured. This paper is a continuation of our previous work. To the best of our knowledge, there are no reports on chemical modification of TiNi alloy by $\mathrm{Ag}$ element in order to improve electrochemical properties of electrode for $\mathrm{Ni}-\mathrm{MH}_{x}$ batteries.

\section{Experimental details}

All materials were synthesized under an argon atmosphere by MA process performed in SPEX 8000 Mixer Mill. Every powder milling lasted $8 \mathrm{~h}$. The purity of Ti, $\mathrm{Ni}$, and $\mathrm{Ag}$ elemental powders used in MA was at least $99.9 \%$. Detailed description of synthesis procedure was described in our previous works $[5,6]$. In this we synthesized two materials: pure TiNi alloy and chemically modified TiNi alloy with $5 \mathrm{wt} \%$ of $\mathrm{Ag}$ added to elemental powder mixture before MA. Performed synthesis leads to formation of amorphous materials $[5,6]$. Obtained powders were additionally annealed in argon atmosphere at $750{ }^{\circ} \mathrm{C}$ for $0.5 \mathrm{~h}$ to form TiNi CsCl-type structure. In order to verify another way of chemical modification TiNibased composite was produced. This composite was done by 5 min mixing of MA and annealed TiNi alloy with 5 wt\% of Ag in SPEX 8000 Mixer Mill.

To facilitate the reading of work obtained materials were labeled as follows:

- TiNi alloy without changes is labeled as TiNi,

- TiNi with 5 wt\% of Ag nanocrystalline alloy is labeled as $\mathrm{TiNi}+\mathrm{Ag}$,

- Composite of TiNi alloy with 5 wt\% of Ag elemental powder is labeled as $\mathrm{TiNi}+(\mathrm{Ag})$. 
Structure, microstructure, and morphology of materials were studied by X-ray diffraction (XRD) using $\mathrm{Cu} K_{\alpha}$ and scanning electron microscopy (SEM). Average crystallite size were calculated using the Scherrer equation. Based on SEM pictures particle size dimension distribution histograms were made. Each of histogram was made by counting about one thousand of crystal agglomerates.

Corrosion resistance behavior was examined during potentiodynamic tests in $6 \mathrm{M} \mathrm{KOH}$ solution with scanning range and speed -1.5 to $1 \mathrm{~V}$ and $1 \mathrm{mV} / \mathrm{s}$, respectively, on Solatron 1285 potentiostat.

For electrochemical measurements obtained materials were mixed with $10 \mathrm{wt} \%$ additional NI powder and cold pressed under $800 \mathrm{MPa}$ to form pellets. This pellets were used as negative electrodes in $\mathrm{Ni}-\mathrm{MH}_{x}$ systems. Electrochemical measurements were performed in $6 \mathrm{M}$ $\mathrm{KOH}$ solution using Multi-channel Battery Interface ATLAS 0461. Electrodes were charged and discharged at $40 \mathrm{MA} / \mathrm{g}$. A cut-off potential vs. $\mathrm{Hg} / \mathrm{HgO} / 6 \mathrm{M} \mathrm{KOH}$ was $-0.7 \mathrm{~V}$. Cycle stability was evaluated by capacity retaining rate after 18 th cycle

$$
R_{\mathrm{h}}=\frac{C_{18}}{C_{\max }} \times 100 \%,
$$

where $C_{18}$ and $C_{\max }$ are discharge capacities at the 18th cycle and maximum discharge capacity, respectively. Fully description of activation procedure and electrochemical measurements were described in our previous papers $[5,6]$.

\section{Results and discussions}

TiNi-based materials were characterized by XRD, SEM, corrosion and electrochemical measurements. 8 hours of mechanical alloying of $\mathrm{Ti}$ and $\mathrm{Ni}$ elemental powders lead to formation of amorphous phase without creation of any new crystalline phase [6]. Addition of Ag to mixture of elemental powders did not affect MA process (not shown here). Amorphous powders were annealed at $750{ }^{\circ} \mathrm{C}$ for $0.5 \mathrm{~h}$. Figure 1 shows XRD spectra of

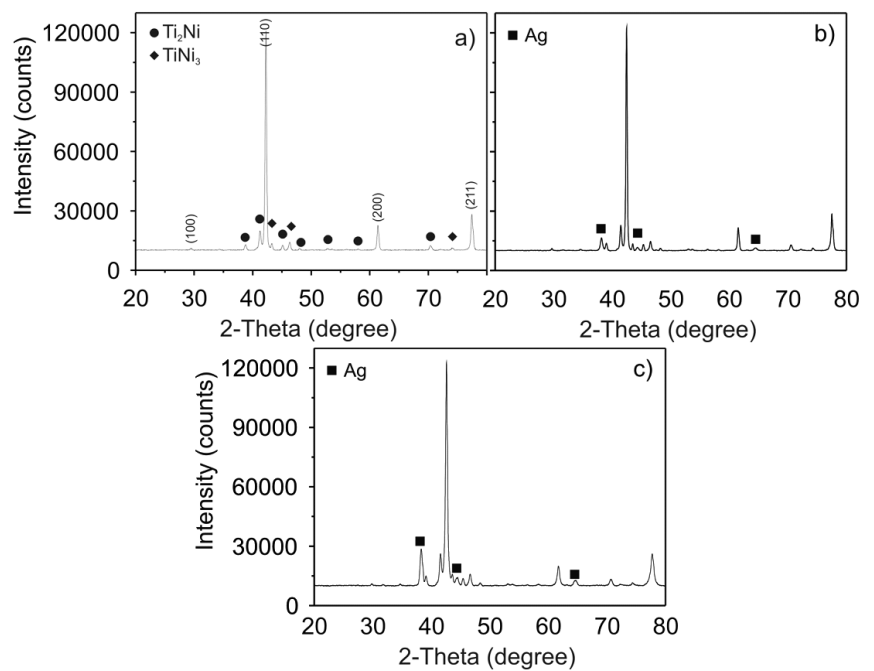

Fig. 1. XRD spectra of obtained powders of: (a) TiNi alloy, (b) $\mathrm{TiNi}+\mathrm{Ag}$, (c) $\mathrm{TiNi}+(\mathrm{Ag})$. obtained materials. The most intense peaks are related to presence of TiNi phase. Additionally to this main phase two minor phases were detected: $\mathrm{Ti}_{2} \mathrm{Ni}$ and $\mathrm{TiNi}_{3}$. On XRD pattern assigned to $\mathrm{TiNi}+\mathrm{Ag}$ small peaks associated with presence of Ag crystals are visible. The same peaks were also visible on XRD spectra related to $\mathrm{TiNi}+(\mathrm{Ag})$ composite (Fig. 1c). However, the intensity of these peaks were much higher for TiNi based composite. Taking into account that both materials have the same amount of silver, we think that part of silver in $\mathrm{TiNi}+\mathrm{Ag}$ alloy could react with $\mathrm{Ti}$ and $\mathrm{Ni}$ creating $\mathrm{Ti}-$ $\mathrm{Ni}$ based phase $\left(\mathrm{TiNi}, \mathrm{Ti}_{2} \mathrm{Ni}, \mathrm{TiNi}_{3}\right)$. Rest of elemental $\mathrm{Ag}$ did not react with other elements which is visible on XRD spectra. Based on XRD date, average crystalline size were calculated using the Scherrer equation. Silver addition does not significantly affect the crystallite size which equaled 26 and $28 \mathrm{~nm}$ for unmodified and modified alloys, respectively (Table I).

TABLE I

Crystallites size and average particle size of TiNi-based materials.

\begin{tabular}{c|c|c}
\hline \hline Composition & $\begin{array}{c}\text { Crystallites size } \\
\text { of annealed powders } \\
{[\mathrm{nm}]}\end{array}$ & $\begin{array}{c}\text { Average agglomerates } \\
\text { size of annealed } \\
\text { powders [pm] }\end{array}$ \\
\hline $\mathrm{TiNi}$ & 26 & 25.5 \\
$\mathrm{TiNi}+\mathrm{Ag}$ & 28 & 26.7
\end{tabular}

Figure 2 shows SEM pictures of $\mathrm{TiNi}$ and $\mathrm{TiNi}+\mathrm{Ag}$ alloys. In both cases crystallite agglomerates had size from a few to one hundred of $\mu \mathrm{m}$. MA and annealed materials had cleavage fracture morphology (Fig. 2a). Based on SEM pictures particle size dimension distribution histograms were made (Fig. 3). Most of agglomerates had size less than $50 \mu \mathrm{m}$. Average size of agglomerates is similar for $\mathrm{TiNi}$ and $\mathrm{TiNi}+\mathrm{Ag}$ alloys and equaled a little bit more than $25 \mu \mathrm{m}$ (Table I). Particle size dimension distribution of $\mathrm{TiNi}+\mathrm{Ag}$ is more uniform.

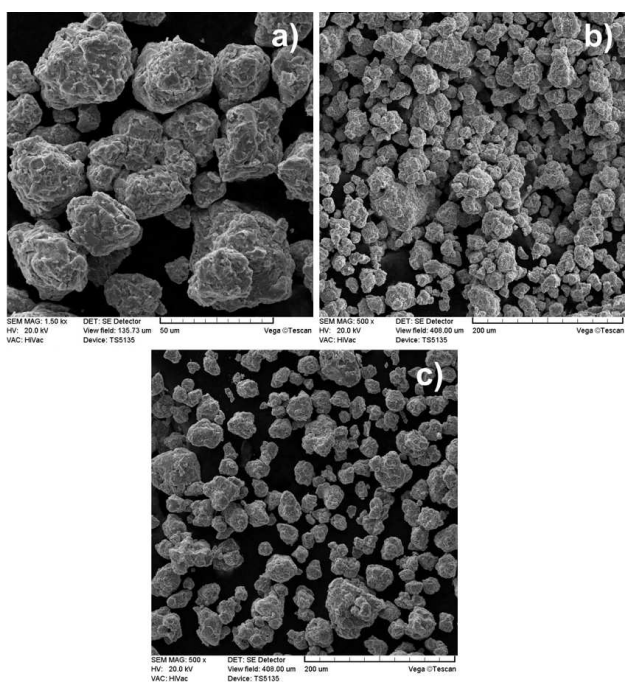

Fig. 2. SEM picture of TiNi (a,b) and $\mathrm{TiNi}+\mathrm{Ag}(\mathrm{c})$. 


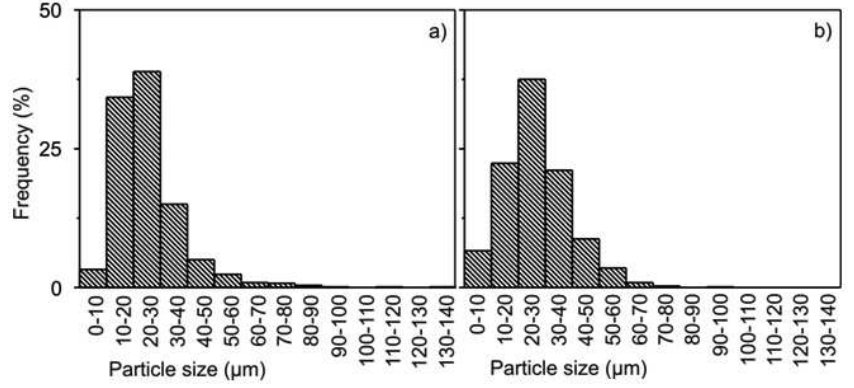

Fig. 3. Particle size dimension distribution histograms of: (a) $\mathrm{TiNi}$, (b) $\mathrm{TiNi}+\mathrm{Ag}$.

The potentiodynamic polarization behavior of the uncharged studied alloys is given in Fig. 4. Curves had a very similar shape for all tested materials. Initially occurring area of resistance is followed by active dissolution of formed hydroxide layer. Then, the passivation process is observed during which the hydroxide layer is rapidly formed. The hydroxidation process has been disturbed for some reason, resulting in a creation of new clean surface. The surface was quickly hydroxidized to reach the passive state. Corrosion current for all of the powders is summarized in Table II. It is shown that $\mathrm{Ag}$ in TiNi alloy and composite improves the corrosion resistance of materials in alkaline solution. The best corrosion resistance was observed for $\mathrm{TiNi}+(\mathrm{Ag})$ composite. This slight improvement of corrosion properties probably resulted from suppressed pulverization of electrode due to the anticorrosion effect of silver addition.

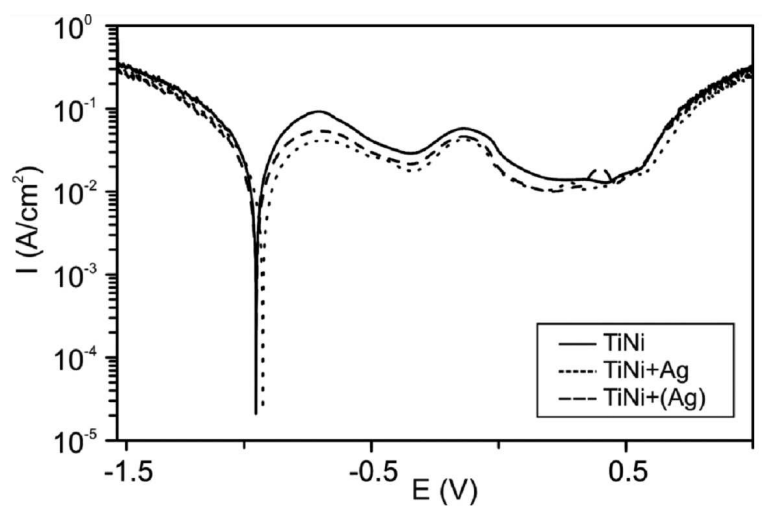

Fig. 4. Potentiodynamic curves of TiNi-based materials in $6 \mathrm{M} \mathrm{KOH}$ solution.

Table II and Fig. 5 reports electrochemical properties of studied materials. All electrodes are characterized by good activation properties. The maximum discharge capacity of studied alloys and composite was obtained in 2 nd or 3rd cycle. The highest discharge capacity showed $\mathrm{TiNi}+\mathrm{Ag}$ alloy $-173 \mathrm{mAh} / \mathrm{g}$. MA and annealed TiNibased materials displayed higher discharge capacity than that the arc ones [9]. Discharge capacities for all studied materials decreased during next cycles of charging and discharging. It is probably caused by formation of
TABLE II

Maximum discharge capacity, capacity retaining rate after 18th cycle, corrosion current of TiNi-based materials.

\begin{tabular}{c|c|c|c}
\hline \hline Composition & $\begin{array}{c}\text { Max. discharge } \\
\text { capacity } \\
{[\mathrm{mAh} / \mathrm{g}]}\end{array}$ & $\begin{array}{c}\text { Capacity retain- } \\
\text { ing rate after } \\
18^{\text {th }} \text { cycle }[\%]\end{array}$ & $\begin{array}{c}\text { Corrosion } \\
\text { current } \\
{\left[\mathrm{A} / \mathrm{cm}^{2}\right]}\end{array}$ \\
\hline $\mathrm{TiNi}$ & 171 & 65 & $2.33 \times 10^{-2}$ \\
$\mathrm{TiNi}+\mathrm{Ag}$ & 173 & 76 & $1.79 \times 10^{-2}$ \\
$\mathrm{TiNi}+\mathrm{Ag})$ & 159 & 84 & $1.19 \times 10^{-2}$
\end{tabular}

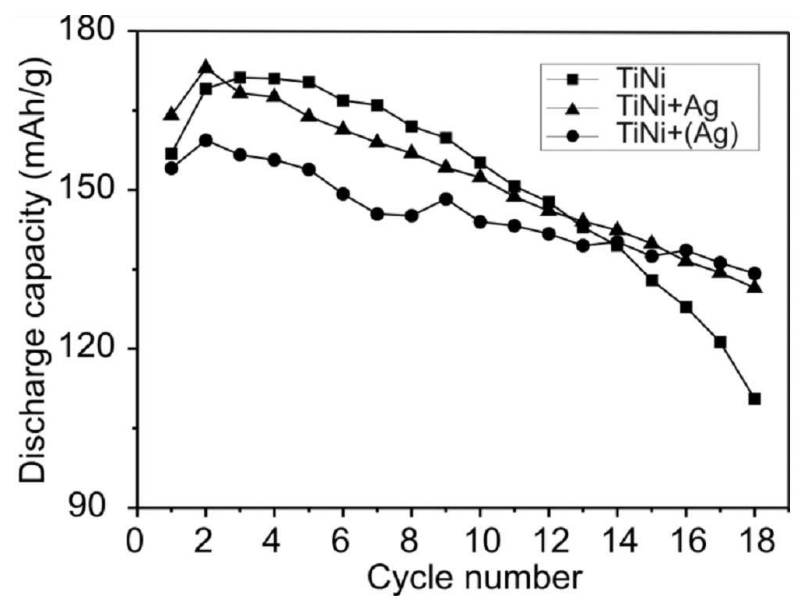

Fig. 5. Discharge capacities as a function of cycle number of electrode prepared with TiNi-based materials (solution $6 \mathrm{M} \mathrm{KOH}$, room temperature).

oxides, hydroxides, and irreversible hydride phases. Created hydroxide layer acted as a barrier for the atomic hydrogen in and out diffusion and the materials electrochemical performance deteriorated with charge/discharge cycles. A positive effect of $\mathrm{Ag}$ addition can be related to creation of easy diffusion pathways trough the hydroxide layer for atomic hydrogen. It could be also caused by selective dissolving of hydroxide layer making it more porous and less stable which is favorable for hydrogen transport. $\mathrm{TiNi}+(\mathrm{Ag})$ is characterized by the best capacity retaining rate after 18 th cycle, which equaled $84 \%$.

\section{Conclusions}

TiNi-based alloys and composites with Ag prepared by MA and annealing were used as negative electrodes for $\mathrm{Ni}-\mathrm{MH}_{x}$ rechargeable batteries. Based on this study the following conclusions can be obtained:

- Chemical modification of TiNi alloy by 5 wt\% of Ag element does not affect crystallite size and average agglomerate size.

- Ag particles improves corrosion resistance of TiNi alloy in alkaline solution.

- TiNi with 5 wt\% composite is characterized by the best cycle stability during electrochemical tests which equaled $84 \%$ after 18 cycles. 


\section{References}

[1] E. Jankowka, M. Makowiecka, M. Jurczyk, Renew. Energ. 33, 211 (2008).

[2] C.S. Wang, Y.Q. Lei, Q.D. Wang, J. Power Sources 70, 222 (1998).

[3] J. Liu, X.P. Gao, D.Y. Song, Y.S. Zhang, S.H. Ye, J Alloys Comp. 231, 852 (1995).

[4] R.A. Varin, T. Czujko, Z.S. Wronski, Nanomaterials for Solid State Hydrogen Storage, Springer, New York 2009.
[5] M. Balcerzak, M. Jurczyk, Inzynieria materialowa 5, 370 (2012) (in Polish).

[6] M. Balcerzak, M. Nowak, J. Jakubowicz, M. Jurczyk, Renew. Energ. 62, 432 (2014).

[7] R.J. Shih, Y.O. Su, T.P. Perng, J. Alloys Comp. 353, 283 (2003).

[8] B. Huang, P. Shi, C. Lu, Z. Liang, M. Chen, Rare Metal Mater. Eng. 34, 557 (2005).

[9] C.B. Jung, K.S. Lee, J. Alloys Comp. 253-254, 605 (1997). 